\title{
SETBACKS TO THE IMPLEMENTATION OF THE NATIONALLY APPROPRIATE MITIGATION ACTIONS: CASE STUDIES OF THE NAMAS OF ETHIOPIA, GEORGIA AND INDONESIA
}

\author{
Sule AyANNOR IsSAKA \\ Institute of Geography, University of Cologne, Cologne, Germany \\ Manuscript received: April 2, 2021 \\ Revised version: May 31, 2021
}

\begin{abstract}
ISSAKA S.A., 2021. Setbacks to the implementation of the nationally appropriate mitigation actions. Case studies of the NAMAs of Ethiopia, Georgia and Indonesia. Quaestiones Geographicae 40(3), Bogucki Wydawnictwo Naukowe, Poznań, pp. 33-44.

ABstRAct: The lack of implementation of the Nationally Appropriate Mitigation Actions (NAMAs) of the non-Annexe I Parties registered in the NAMA Registry of the United Nations Framework Convention on Climate Change (UNFCCC) is a worrying situation in the sense that it is limiting the contributions these NAMA projects would have made towards mitigating global climate change. There is however little research on the reasons behind the lack of implementation of these NAMAs projects and this is the knowledge gap that this paper seeks to fill based on a critical overview of the NAMAs of Ethiopia, Indonesia and Georgia. The source of data for this paper is mainly from the focal persons for the NAMAs of the countries under study, which was obtained via telephone and Skype interviews with the respondents. Our findings show that lack of funding, complicated financial mechanisms, lack of technical expertise, fringe conditions to donor support and policy issues according to the findings of this study are the main hindrances to the implementation of NAMAs. International organisations, donor partners, developed countries and local governments alike are therefore encouraged to channel some of the funds meant for fighting global climate change into sponsoring the NAMAs of poorer countries, as this will see to the successful implementations of these NAMAs and their subsequent impacts on mitigating global climate change. The paper is also timely considering the scarcity of literature on NAMAs related issues.
\end{abstract}

KEYwords: Nationally Appropriate Mitigation Actions, climate change, UNFCCC, Global South

Corresponding author: Sule Ayannor Issaka; Aisule09@hotmail.com

\section{Introduction}

Concerns about the increasing threats posed by global climate change on lives and property call for the strengthening of efforts towards mitigating global climate change and its multifaceted impacts. This also includes the formulation and efficient implementation of policies in this regard. The formulation and subsequent implementation of climate change mitigation policies also come along with some collateral benefits (Bollen et al. 2009). For instance, climate change mitigation policies geared towards increasing the usage of clean energy and energy-efficient technologies are also likely to bring about improvements in the quality of the local air, which will subsequently lead to improvements in human health and the environment in general (Bollen et al. 2009). It has, however, been noted that most of the already implemented policies aimed at mitigating climate change are primarily focused on 
designing instruments for pricing carbon dioxide and other greenhouse gasses emissions (Aldy et al. 2011). Answers also need to be provided to specific questions in the design of policies for mitigating climate change. Two such questions, according to Büchs et al. (2011), are as follows: how do the burdens of climate change mitigation policy on citizens relate to household income? Are such burdens proportional to the impact on the environment of different lifestyles? And how can climate change policies be designed such that unjust distributional effects are avoided? Finding answers to the above questions is critical in the sense that the likelihood of governments to implement the formulated climate change mitigation policies depends on the acceptance of such policies by the general public (Büchs et al. 2011).

Though climate change has been labelled by some as the most serious of all the environment-related problems of the 21st century both in terms of the magnitude of risk and the affected number of people (Sundstrom 2010), the response of some governments, not only at the local levels but also internationally, has not been forthcoming. This is so because perceiving climate change as a global problem makes it difficult for nations to prioritise climate-change-related issues and to reconcile the interests of the population of the globe to those of their citizens or national interests (Sundstrom 2010). It has therefore been suggested that to know the impacts of climate change mitigation policies on poverty, for instance, it will be prudent to first and foremost examine the specific macroeconomic impacts or effects of such policies (Hussein et al. 2013). This means for the success of any policy geared towards mitigating climate change, a full commitment is needed from all the countries in the world. In this regard, the Third Assessment Report of the Working Group III of the Intergovernmental Panel on Climate Change (IPCC) has called upon the developing world to contribute towards the mitigation of global climate change (Metz 2007). This is the brainchild for the formation of the 'Nationally Appropriate Mitigation Actions (NAMAs)', as it was coined by the United Nations Framework Convention on Climate Change-Secretariat (UNFCCC) during the 18th Conference of the Parties (COP 18) in Doha in 2007. The NAMAs are therefore regarded as initiatives by the UNFCCC to enable poorer countries to meet their climate change mitigation targets (Amars et al. 2017). The NAMAs policy called for formulation of designs by Parties from the developing world of NAMAs, which should be in line with their local sustainable development plan. These NAMAs are expected to be supported by the developed Parties in the areas of technology, finance and capacity building to ensure their preparations and subsequent implementations (Jung et al. 2010). It is, however, regrettable to realise that most of these NAMAs designed by Parties from the developing world and registered on the NAMA Registry of the UNFCCC have since not been moved forward by ways of preparation and/or implementation.

This paper, therefore, seeks to investigate the reasons why most of these NAMAs are yet to be moved forward in terms of preparation and subsequent implementation, drawing references from the NAMAs of Ethiopia, Indonesia and Georgia. Following this introduction is a review of literature on NAMAs and then the research method and study areas. This will be followed by the results section, discussion and then a conclusion.

\section{The formation of the NAMAs, challenges and the way forward}

The NAMAs first came to light in 2007 during the Bali Action Plan (UNFCCC 2009). It is regarded as a crucial component and a cornerstone for combating global climate change (UNFCCC 2009). The Copenhagen Accord in 2009, which was presented during the 15th COP meeting in Copenhagen, was climaxed by the submission of some developing countries, of their NAMAs to the UNFCCC (Linnér, Pahuja 2012). According to Linnér Pahuja (2012), the following three main arguments were forwarded in favour of the formation of the NAMAs. First, NAMAs might be the beginning of a more significant contribution and binding commitment on the part of developing countries towards mitigating global climate change. According to the proponents of the formation of NAMAs, NAMAs could provide the pathway for developing countries to also carry a portion of the burden of the climate change fight, and that is needed to achieve global emission reductions. Secondly, NAMAs are promising to serve as a new era in the history of the UNFCCC whereby the world can count on more voluntary efforts and contributions towards emission reductions. 
This is undoubtedly a prerequisite for the success of any global climate change treaty, an example of which has just been demonstrated by China and the USA when they rectified the declaration of the Paris Conference. Lastly, a future state or regime of global climate change mitigation efforts might come to supplement the efforts of the developed countries that are under a binding climate change mitigation commitment to achieve a threshold for emissions based on the principle of common but differentiated responsibilities.

It has however been noted that several issues, especially at the helm of the affairs of international policies regarding the development of NAMAs, their implementation, and the support available for NAMAs, are yet to be well defined. This means that presently there is no formal definition regarding what a NAMA should be like (Linnér 2012). Some of the challenges that emanated during the early days of the inception of the NAMAs agreement were that there was no official definition for what NAMAs should be and no platform for registering proposed NAMAs. There was also no assistance available for NAMAs in the areas of finance and technology (Röser et al. 2012). As a result, the NAMA Registry, which served as a one-stop-shopping point for NAMAs in need of support for preparation, implementation or recognition, was formed by the UNFCCC secretariat. The NAMA Registry platform also showcases support available for NAMAs from donor countries and partners that could be solicited by the developing Parties for the preparations and implementations of their NAMAs.

The COP during its 16th annual session decided to establish, and commit to, the operation of a NAMA Registry. The key functions of the registry are to record NAMAs of developing Parties, facilitate finance matching, assist in capacity building coupled with the needed technology and showcase available supports for NAMAs (UNFCCC 2013). In this regard, the COP extends an invitation to the non-Annexe I Parties to submit to the UNFCCC secretariat, information on their respective NAMAs, seeking support for either preparation, implementation with the estimated financial cost and time needed for complete implementation of such projects (Khan 2016, UNFCCC 2013). Again, the COP has extended an invitation to the developed countries and donor agencies, together with international and multilateral financial institutions such as the Green Climate Fund, Global Environment Facility, bilateral and multilateral partners, and non-governmental organisations to provide the UNFCCC with information on the specific supports that they can provide either for preparation or implementation of registered NAMAs (Khan 2016). Consequently, the COP requested that the UNFCCC secretariat should be providing it with information on the annual operation of the NAMA Registry to enable it to make known information on available financial mechanisms (UNFCCC 2013).

There are, however, variations on the type NAMAs registered according to the region of origin. While the NAMAs from Africa and the Least Developed Countries (LCDs) are mostly still at the preparation stage and are thus seeking support for preparation, NAMAS from regions such as the Small Island Developing States (SIDS), eastern Europe, Latin America and the Caribbean are mostly registered just for recognition (UNFCCC 2010). This is because these Parties are capable of sponsoring the preparation and implementation of their NAMA projects without external support. As of 2015, a total of 152 NAMAs were in the development process while 13 had already received funding for implementation (Lachlan et al. 2015). This is undoubtedly an improvement on the 53 submissions 3 years after the inception of the NAMAs. As a part of the agreement that led to the formation of the NAMAs, the UNFCCC made it known that the likelihood of developing countries to meet their targets of mitigating climate change will largely depend on the support they receive from the developed world by ways of finance, capacity building and technology (Friman et al. 2014). This will also enable these countries to be recognised for their roles in global climate change mitigation efforts (IRENA 2014). This leads us to the main hypothesis of this paper which is: developing countries lack the needed financial resources and technical expertise for the successful implementation of NAMA projects.

Critics of the NAMAs policy argued that the issue of 'national appropriateness' as expected of each NAMA varies from one country to another. This according to the critics' opinions, render the NAMAs concept vague and subject to varied interpretations (Sharma Desgain 2013). Other important issues regarding the NAMAs that need clarifications include the question of 'what 
qualifies to be called support', and also how to correlate funds with specific intentions but geared towards the implementation of NAMAs (Friman et al. 2014). Despite the above-noted shortfalls of the NAMAs, it has been argued that properly designed NAMAs could become avenues for developing countries to execute or promote their ambitious programmes by taking advantage of climate finances while fulfilling the demands of the donor countries or partners at the same time (Sharma Desgain 2013). There has also been a call on sectoral NAMAs to foster collaborations with very prominent and high emitting organisations or sectors while attracting investments in lower-carbon technologies at the same time (IRENA 2014). Sectoral NAMAs should also put efforts into raising the awareness of available business opportunities that can be derived in NAMA projects (IRENA 2014).

\section{Research methods and study areas}

\section{Research method}

In total, seven NAMAs from all three countries (three from Ethiopia, two from Indonesia, and two from Georgia) have been covered under this study. The breakdown is provided below.

\section{Ethiopia}

1. NS-167 - Ethiopia Railway's Adis Ababa Light Rail Transit (LRT) Transit-Oriented Development (TOD) NAMA (NAMA seeking support for preparation).

2. NS-173 - Ethiopian Railways-Railway Acadamy NAMA (NAMA seeking support for preparation).

3. NS-168 - Ethiopia Railways-Establishment of Climate Vulnerability Infrastructure Investment Framework NAMA (NAMA seeking support for implementation).

\section{Georgia}

1. NS-229- Efficient use of biomass for equitable, climate-proof and sustainable rural development (NAMA seeking support for implementation).

2. NS-228- Energy Efficient Refurbishment in the Georgian Public Building Sector (NAMA seeking support for implementation).

\section{Indonesia}

1. NS-65 - Sustainable Urban Transport Initiative NAMA (NAMA seeking support for implementation).

2. NS-89 - Smart Street Lighting Initiative NAMA (NAMA seeking support for implementation).

The findings of this study were achieved through telephone and Skype interviews with officers (focal persons) of the NAMAs focal points of all the three countries under study. The NAMAs focal point of a country is the body responsible for the NAMAs of that country and thus a one-stop-shopping point for any information concerning the NAMAs of that particular country. The officials are the NAMA focal persons. The NAMA focal persons are involved in one way or another in the formulation, preparation or implementation of their NAMAs. The names and contact details of these NAMAs officials of the respective countries were derived from the NAMA Registry of the UNFCCC as these contact details are always attached to the NAMAs from various countries that are entered within the NAMA Registry. The use of telephone and Skype interviews as a method in qualitative data collection has become a mainstream means of data-procurement and is accepted as a method in qualitative research especially in industrialised and developed countries (Lo-lacono Valeria et al. 2016). One main advantage of telephone and Skype interviews is that respondents tend to feel freer and more relaxed and are therefore able to disclose relevant information in a more detailed manner (Farooq 2015). Another benefit of conducting telephone and Skype interviews is that it helps save money and time in terms of travelling for longer distances to collect data. It is an efficient method when it comes to the safety of participants or respondents, and it is an efficient method to be used when respondents are geographically dispersed as is the case in this study (Farooq 2015).

There were telephone and Skype interviews with the focal persons responsible for NAMAs of their respective countries. The method can, therefore, be called expert interviews as respondents were specifically selected based on their insight and in-depth knowledge regarding the NAMAs of their respective countries. As the NAMAs focal point, they are expected to know the state of their 
respective NAMAs that were registered with the NAMA Registry of the UNFCCC. They are expected to know whether their respective NAMAs are in the state of preparation or implementation, the source of funding for the preparation or implementation of the NAMAs and the setbacks to the preparation and subsequent implementation of these NAMAs.

The NAMA focal point for each of the countries was first contacted via email to request an appointment for either a phone or Skype interview. The date and time for either the telephone or Skype interview were negotiated upon, and an agreement was reached. Sample questions were sent to the interviewee(s) to give them an idea of the information that would be required from them during the interview. An interview guide, with open-ended questions, was used for all the participants and each interview lasted between $2 \mathrm{~h}$ and $3 \mathrm{~h}$. The interviews were recorded with an audio device and transcribed later. There was also note-taking of key points as the interviews were ongoing - not only to serve as back-ups but also to serve as a guide for the subsequent questions. Another important source of data for this study is secondary sources. Secondary sources are constituted mainly by secondary data from the NAMAs' focal point of each of the countries under study, and they include proposals for their respective NAMAs, the final versions of their NAMAs as they have been submitted to the NAMA Registry of the UNFCCC and funding documents.

The above countries were selected after a preliminary survey of the capacity-building needs in the preparation and implementation of NAMAs in developing countries. This initial survey which I conducted for the UNFCCC secretariat covered 33 Non-Annexe I countries and 77 different NAMAs in all. These 33 countries are among many others who entered their NAMAs into the NAMA Registry of the UNFCCC for availing secure funding and/or technical support to enable them to move their respective NAMAs forward. One major reason for selecting Ethiopia, Indonesia and Georgia for this study is that these countries all had NAMAs in all the three different stages of the development of a NAMA, which are formulation, preparation and implementation stages. They can, therefore, serve as role models to other countries that are still struggling to formulate their NAMAs. The three countries also have NAMAs in different sectors of their economy, which grants the opportunity of comparing the situations between different NAMAs both within a country and among countries.

It must, therefore, be noted that there are likely to be similarities in the findings of this paper with that of the NAMAs documents, proposals or any other document concerning the NAMAs of the above study countries. This is mainly due to the source of data used in this study and the respondents involved, as has been explicitly outlined above.

\section{Study areas}

\section{Ethiopia}

Ethiopia, one of the most populated countries in Africa, had an estimated total population of 112 million in 2019 (United Nations 2019). The country has historically been linked with very extreme weather and climatic events (Robinson et al. 2013). Ethiopia is situated in the eastern part of the continent of Africa with a total landmass of $1,104,300 \mathrm{~km}^{2}$, and an economy largely vulnerable to climatic variability (Conway, Schipper 2011). Agriculture, which is predominantly rain-fed and thus influenced by fluctuations in the amount and duration of rainfall, is the primary occupation of most Ethiopians, just like most African countries (Conway, Schipper 2011, United Nations 2019). Annual rainfall figures in Ethiopia vary widely from $3000 \mathrm{~mm}$ around Masha in the Baro-Akobo Basin to as low as $200 \mathrm{~mm}$ around the areas of the Ethiopia-Somalia and Ethiopia Dibouti borders in places such as the Aysha and Ogaden Basins (Government of Ethiopia 2015). Less than $20 \%$ of the Ethiopian population dwells in and around urban areas, making the population of the country predominantly rural (Government of Ethiopia 2015).

Ethiopia is vulnerable to climate change, especially in sectors such as agriculture, human health and water (Gashaw et al. 2014). There is, however, recent concern over the increasing aggregate of greenhouse gas emissions in the country, as estimated emissions for 2013, for instance, are said to be about $447 \%$ higher than that of 1994 (Gashaw et al. 2014). Increased forestation initiatives have however boosted the carbon of 
the country in the LUCF sub-sector: to be specific, from $7 \%$ to $14 \%$ during the $1994-2013$ period (Zerga, Gebeyehu 2016).

\section{Georgia}

Georgia, a former colony of the then Soviet Union, is situated in the southern part of the Caucasus in-between the Caspian Sea and the Black Sea and the south of the Great Caucasus Mountains (MENRPG 2015). Georgia shares borders with countries such as the Russian Federation, Azerbaijan, Armenia and Turkey (MENRPG 2015). The country lies in-between Latitudes $41^{\circ}$ and $43^{\circ} \mathrm{N}$ and longitudes $40^{\circ}$ and $46^{\circ} \mathrm{N}$ of the equator, with a total land area of 26,911 square miles (Swithin Lui 2018). Georgia has a population of about four million (Swithin Lui 2018).

Georgia's climate is very diverse with almost all climatic types; nonetheless, the country can still be categorised into two distinct climatic regions, namely the humid subtropical climate around the west of Georgia and the dry subtropical climate in the eastern part of the country (Amiranashvili et al. 2005). Both temperature and precipitation rates also vary significantly by region, as per the topography of the area (Georgia's Second National Communication to the UNFCCC Tbilisi 2009). For instance, the average annual temperature in the lowland areas of western Georgia and the coastal zones of the Black Sea is between $14^{\circ} \mathrm{C}$ and $15^{\circ} \mathrm{C}$, while precipitation ranges from 1500 to $2700 \mathrm{~mm}$ (Georgia's Third National Communication to the UNFCCC 2015). In the lowlands of the eastern part of the country, the average annual temperature is between $11^{\circ} \mathrm{C}$ and $13^{\circ} \mathrm{C}$. However, the impacts of climate change since the last twoand-half decades have seen temperatures in the west of Georgia increasing by $0.3^{\circ} \mathrm{C}$ and that of the east of Georgia by $0.4-0.5^{\circ} \mathrm{C}$ (Georgia's Third National Communication to the UNFCCC 2015).

Georgia is said to have experienced a decline in its greenhouse gasses emission rates, which has been attributed to the decrease in the supply of energy and raw materials after departing from the Soviet Union (Swithin Lui 2018). Some also attributed this to other factors, such as the global financial crisis of 2008-2010 and the war of 2008 (USAID 2016). The main source of the country's total energy supply as of 2014 was predominantly fossil fuels $(66 \%)$, obtained mainly from oil products and natural gas, with hydropower contributing 16\% and the rest from biomass (Swithin Lui 2018). Nonetheless, the country has been making significant strides to contribute its part towards mitigating global climate change, such as the ratification of the Paris agreement and the submission of their first Nationally Determined Contribution in 2017 (Swithin Lui 2018). With the support of the government of the USA, Georgia commenced the preparation of its Low Emission Development Strategy (LEDS) in 2013, with the target of cutting down emission rates to $<15 \%$ by 2030, which is below the business-as-usual scenario (USAID 2016).

\section{Indonesia}

Indonesia, a country located within latitudes $6^{\circ} 08^{\prime} \mathrm{N}-11^{\circ} 15^{\prime} \mathrm{S}$ and longitudes $94^{\circ} 45^{\prime}-141^{\circ} 05^{\prime} \mathrm{E}$, has an estimated population of 220 million as of 2005 (Badan Pusat Statistik 2019). Indonesia is undeniably another hot spot for extreme climate events in the world. Indonesia, the fourth most populated country worldwide, trailing behind China, India, and the USA, occupies a landmass of $1,910,931 \mathrm{~km}^{2}$ with five major islands, namely Sumatra, Kalimantan, Java, Irian Java and Sulawesi (Badan Pusat Statistik 2019). About 50 million acres out of the total land territory of 200 million acres of Indonesia is underused for different kinds of agricultural activities, 20 million of which are arable land (Barichello, Patunru 2009).

Indonesia is said to be the third-largest emitter of greenhouse gasses in the world, mostly emanating from forest fires and environmental degradation as well, rather than from industries as has always been the case of major emitting countries (Baba 2010). Due to factors such as topography, location and other socio-economic related causes, the country is suffering from the impacts of climate change and climate variability, which is affecting food security and the overall economy of the country (Rizaldi et al. 2017). This prompted the Ministry of Environment and Forestry to develop a tool for assessing the vulnerability rate of the village people to climate change known as the SIDIK, which is a 'Vulnerability Index Information System' (Rizaldi et al. 2017). Indonesia has, however, pledged to reduce its emission rate by $26 \%$ through its efforts and initiatives and up to $41 \%$ by 2020 , with the help of the international community, based on business as 
usual (Susandi 2004). A significant step towards achieving this goal is the implementation of the 'NAMA-SUTRI', which stands for the Sustainable Urban Transport Program of Indonesia (Susandi 2004). Also, Indonesia is said to have benefitted from several donations from the international community, and the country is said to have secured a total of $\$ 4.4$ billion of financial support to deal with climate change for several years to come (Peskett, Brown 2011). In the approved National Action Plan for tackling climate change, Indonesia again aims at the integration of climate change mitigation and adaptation actions (Thuy et al. 2014). It has, however, been noted that for Indonesia to meet its targets for greenhouse gas reduction as stated in the country's nationally determined contribution, the country will need to prioritise the implementation of the climate change abatement action (World Resources Institute 2017). This also requires other stronger measures, such as the implementation of energy conservation programmes, restoration of degraded peatlands, increasing the forest cover of the country and the pursuance of mitigation actions or measures in other sectors of the country's economy, such as gases (Permadi et al. 2017). These measures are especially needed if the country is committed to achieving the targeted $41 \%$ reduction by 2030, under the business-as-usual scenario (Permadi et al. 2017).

\section{Results}

The findings of this study have shown the following setbacks to the implementations of the NAMAs of the countries under study, as recorded in the NAMAs registry of the UNFCCC.

\section{Lack of funding}

The findings of this study have shown that one major obstacle to the preparation and subsequent implementation of almost all the NAMAs under this study is the lack of financial capital. It is important to make the preliminary observation that the NAMAs under study, together with a majority of NAMAs recorded in the UNFCCC-NAMA Registry, are from developing and poorer countries that already have limited budgets for the provisioning of basic amenities for their citizenry (see for instance Metz, Kok 2008). However, being still committed to contributing their quota to mitigating climate change, these countries welcome the call to record their NAMAs on the UNFCCCNAMA Registry, thereby ensuring that procurement of funding from donor agencies, developed countries and also bilateral and multilateral partners is made possible, which would enable them to prepare and/or implement these NAMA projects. For instance, the findings of this paper show that all three NAMAs of Ethiopia listed above are faced with the problem of limited finances as the major setback to their successful preparation and implementation. The transport NAMA of Indonesia, according to the findings is also faced with the problem of inadequate funding that is hindering its implementation. The respondent added that only half of the amount pledged by the NAMA facility fund for the implementation of the transport NAMA of Indonesia has been fulfilled. This has resulted in a halt in the implementation of this NAMA project. He added that though the government of Switzerland also expressed interest in supporting the implementation of the transport NAMA, this has however remained a pledge. In installing heating systems in public buildings in the country, the Georgian NAMA has also been hindered by the problem of lack of funding for its implementation, according to the respondents. The findings also show that Georgia could not secure funding from the NAMA Facility Fund for the implementation of the NAMAs on 'Efficient use of biomass for equitable, climate-proof and sustainable rural development' and the NAMA on 'Energy Efficient Refurbishment in the Georgian Public Building Sector' owing to inability to provide the NAMA facility with a detailed business plan at the time of application. This has therefore halted the implementation process of both NAMAs.

\section{Complicated financial mechanisms and regulations}

Closely related to the issue of absence or insufficiency of funding for NAMAs projects of the countries under study, is the problem of complicated financial mechanisms or regulations for NAMA projects. The findings of this study have shown that there are instances whereby the funding mechanisms for NAMAs were not 
enumerated or clearly communicated to the receiving country (see also Upadhyaya 2012). The findings again show that another source of complication in terms of financing NAMA projects is when one single NAMAs project is being funded from different financial sources. The respondent noted that the transport NAMA of Indonesia is again a case in point for the problem of financial technicalities, and this is said to be impeding the successful implementation of this particular NAMA. The respondent emphasised that this particular project was supposed to be funded by the central government of Indonesia, coupled with the support of local government agencies and donor partners. This kind of procedure according to the respondent is unfamiliar for both the central and local government units. This is therefore said to be causing problems in the implementation processes of the NAMA project. In the case of Georgia, the findings show that there is a problem in the areas of financial schemes that need an urgent solution, to ensure the success of the NAMA that seeks to promote the efficient usage of biomass in public or state buildings of Georgia. This particular NAMA is expected to contribute to the development of rural areas in the country. These financial technicalities according to the respondents sometimes arise because of conflicts of interests and the lack of clear-cut regulations regarding who is supposed to sponsor what and thus hamper the smooth and successful implementation of the NAMA.

\section{Lack of technical expertise}

The findings of this study have also shown that there is also the problem of the lack of expert knowledge that will, for instance, carry out feasibility studies and the preparation and subsequent implementation of the NAMAs projects in the countries under study. The findings show that sometimes countries resort to the hiring of consultants to assist them in carrying out feasibility studies, preparation or implementation of their NAMAs, which comes at an additional cost to them (see for instance Röser et al. 2012). The respondents noted that, in some cases, there is the total absence of the needed expertise for the execution of these NAMAs projects while, in other cases, the very few skilled personnel available refuse postings to rural areas to work on NAMA projects. For instance, the Georgian NAMA for the refurbishment of efficient energy in public buildings of the country, according to the respondents, is faced with the problem of the absence of technical capacity for its implementation. Georgia as a country, according to the respondents, happens to be somehow new in terms of issues regarding NAMAs, and the needed technical capacity for formulating and/ or implementation of these NAMA projects is still lacking. The issue of skilled personnel is an important component of the successful preparation and implementation of NAMA projects. The availability of a good technical capacity will enable the preparation of a good proposal for the NAMAs, and this means that the NAMA project stands a higher chance of receiving funding for its implementation. Some countries, therefore, resort to the hiring of foreign consultants to help them prepare their NAMAs to make them more appealing to donor partners, and this undoubtedly comes at another cost. Besides helping in the preparation of good NAMA proposals, expert knowledge is also needed to help in securing donor support for the implementation of NAMAs. Some countries also lack the know-how of finding and approaching the right donors for their NAMAs, especially when they are doing it for the first time. All these have been blamed for the delays in the implementation of some NAMAs. These findings confirm the main hypothesis of the paper, which states that developing countries lack the necessary financial resources and technical expertise for the successful implementation of NAMA projects.

\section{Fringe conditions attached to donor supports}

Another issue of great concern that is hampering the successful implementation of some NAMAs projects is the fringe conditions that are sometimes attached to supports for NAMAs by donor partners or countries. Some of these fringe conditions are said to be not suitable for the local conditions of the recipient country, while others might have long-term economic, political or socio-cultural consequences on the recipient country (see also Upadhyaya 2012). A case in point is the transport NAMA of Indonesia again. It has been noted that the conditions attached to the donor support for the implementation of this 
NAMA are sometimes not compatible with the interest of Indonesia. This sometimes causes misunderstanding between Indonesia and the donor partners, the result of which is certainly not pleasant for the successful implementation of the NAMA. The issue of fringe conditions - which are always attached to aids of any kind, either from rich countries, donor agencies or bilateral/ multilateral bodies, to poorer countries - is not a new concept, and the resulting consequences are not different from the situation with the NAMAs. These poorer countries are sometimes left with no option other than to accept these aids and grants together with their fringe conditions because of their inability to fund these projects themselves. This is the situation concerning some NAMAs recorded in the UNFCCC-NAMA Registry, in relation to which the transport NAMA of Indonesia is of no exception.

\section{Protocol/policy issues}

The findings again points to policy complications and disagreements at the various levels of policymakers regarding NAMAs, and this certainly slows down the implementation process of these NAMAs. The findings show that issues regarding NAMAs sometimes cut across different sectors of a country, and the inability of the sectors involved to come to a consensus on the implementation of a particular NAMA, which is sometimes the situation, will eventually retard the progress of that particular NAMA. For instance, the Georgian NAMA on Energy Efficient Refurbishment in the Georgian Public Building Sector according to the respondents has encountered some legislative issues that retarded its implementation process. Again, the respondents noted that the NAMA on the efficient usage of biomass in the country is experiencing the problem of lack of cooperation between the Georgian Ministries of Environment and that of Energy, and this paucity in cooperation is said to be hampering the implementation process of the NAMA. This is because this NAMA project has received the necessary attention from the Ministry of Environment, which is trying to ensure that the NAMA project is being implemented. The Georgian Ministry of Energy, on the other hand, according to the respondents is focusing on much bigger projects such as hydropower, which does not bring about many benefits to the target group for this project, the poor rural dwellers. This conflict of interest among the two major ministries responsible for ensuring the success of the NAMA has contributed to bringing the progress of the NAMA to a halt.

\section{Lack of awareness of the general public on issues relating to NAMAs}

There is again the problem of lack of awareness on the part of the general public in the above countries under study regarding NAMAs and this has negative implications in terms of the implementation of NAMAs projects. The findings show that the ignorance of the general public about the motives behind these NAMA projects sometimes leads to the outright rejection or low level of patronage and cooperation for these projects. A case in point is the transport NAMA of Indonesia, which the respondent noted is faced with the problem of lack of public awareness that is hindering the success of its implementation. The respondent, therefore, noted the need for public-awareness creation for the success of the transport NAMA of Indonesia. In the case of Georgia, the respondents also called for the need for public awareness creation for their cooperation in implementing the NAMAs on the energy refurbishment of public buildings in Georgia. The lack of awareness of the general public on NAMAs, coupled with its negative impact on the successful implementation of NAMAs according to the respondents, could be attributed to several issues, among which is the low level of education of the citizenry. As a result, educating the general public on the importance of NAMAs in helping mitigate climate change, among other benefits, will, according to the respondents, increase the cooperation and patronage of the people on NAMA projects, which will go a long way in facilitating the implementation of NAMAs.

\section{Lack of stakeholder cooperation}

Last but not least, the lack of cooperation from different stakeholders is yet another hindrance to the success of NAMAs. The findings have shown that the acceptance of NAMA projects by the different stakeholders in society and the maximum cooperation of these stakeholders are 
requirements for the success of these NAMA projects. According to the respondents, NAMAs do not only need the cooperation of stakeholders in society but their endorsement as well for successful implementations of NAMA projects. In the case of Ethiopia, for instance, respondents noted that the need for stakeholders and parties involved to endorse NAMA projects in order to ensure their successful implementations is a major concern. The respondents, therefore, suggest the need for stakeholder consultations in the formulations of these NAMAs, as this will make them own allegiance to these MANAs and thus result in a commitment to their successful implementations. These stakeholders, who include heads of institutions, chiefs, political leaders, leaders of religious bodies, entrepreneurs and corporate bodies, do have a say in happenings in society and their endorsement and support for NAMAs can go a long way in influencing the success of these NAMAs in their respective societies.

\section{Discussion}

Though there are other important setbacks to the preparation and implementation of NAMAs, such as complicated financial mechanisms, lack of expertise, policy or protocol issues, lack of awareness of the general public on issues regarding NAMAs, fringe conditions attached to donor supports and the lack of stakeholder cooperation, the respondents admitted that almost all these problems can be fixed or taken care of pursuant to the availability of funding. It is worthwhile to reiterate that all the three countries under this study - together with almost all the countries that recorded their NAMAs in the UNFCCC-NAMA Registry-are developing countries with limited budgets for developmental issues. Although climate change and climate change mitigation might be of concern to these countries, it might not be among their scale of preferences due to the already limited funds for the provisioning of basic amenities and solving more pressing problems for their citizenry. It is out of this understanding of the inability of these countries to finance NAMAs with their local resources that the convention that led to the establishment of the NAMAs called on rich, developed and industrialised countries to support or help in preparing and ensuring subsequent implementation of these NAMAs planned for execution in the poorer countries (Michaelowa, Michaelowa 2012). It is also estimated that there is the likelihood of not only the $\$ 30$ billion promised as a starting capital for activities geared towards the climate change mitigation and climate adaptations in countries of the Global South but also the $\$ 100$ billion and above pledged by the developed countries from the year 2020 ending up being used for NAMAs (Michaelowa, Michaelowa 2012). This, when properly done, will lead to the realisation of the second hypothesis of this paper, which states that the NAMAs policy will serve as a door opener for the active involvement of developing and poorer nations in the global fight against climate change.' It has to be noted that though some of these developing countries have successfully prepared and even implemented a few NAMAs with their local resources, this constitutes a minor percentage of the NAMAs recorded in the NAMA Registry, and there is the need for countries to work harder towards the mobilisation of local funds, especially from the private sector, to finance their NAMAs. There is also the need for both developing and developed countries to start mainstreaming NAMAs and climate change mitigation in general into national policies and longterm developmental plans, as this will be a winwin situation of mitigating climate change and achieving economic growth followed by overall development in the long term.

\section{Conclusion}

Among the most important steps ever by the international community's effort aimed at helping poorer countries contribute their quotas to global climate change mitigation efforts is the formation of the NAMAs together with the NAMA Registry, which is currently serving as a platform for showcasing not only the registered NAMAs but also the supports available for such NAMAs. The challenges facing the preparation and implementation of the NAMAs are enormous, when considered in combination with their corresponding impact on the efforts of the internal community in mitigating climate change. The idea behind the formation of the NAMAs can, therefore, be said to be brilliant as 
it encourages developing nations that are low emitters but vulnerable to climate change to significantly contribute to reducing climate change while adapting to its impacts as well. This paper, therefore, calls on countries especially from the developing Global South to step up efforts in the formulation and subsequent registration of their NAMAs on the NAMA Registry of the UNFCCC. Developed countries and donor agencies alike should also step up their efforts in supporting the preparation and subsequent implementation of these NAMAs by way of funding and the provisioning of technical expertise. Governments of developing countries are also advised to abstain from the branding and re-branding of developmental projects which they promise their voters during election campaigns into NAMA projects, as ambiguous projects of such types are less attractive to donor partners and agencies. There is the need for NAMAs and other climate-change mitigating actions to become central in the agenda of nations of the Global South, and such activities should also have the full backing of the legislative instruments and should fit well into the national policies of their respective countries. This is necessary to ensure the efficient implementation of those activities at the national or local levels, with their corresponding effects in helping mitigate global climate change.

\section{Acknowledgment}

I wish to acknowledge the important contributions of all the NAMA focal persons who participated in this study for their in-depth contributions. I am very grateful to reviewers for their painstaking multiple reviews freely given.

\section{References}

Aldy J.E., Pizer W.A., Diringer E., Heutel G., Houser T., Levinson A., Lewis J., Lin S., Mcausland C., Popp D., 2011. NBER working paper series the competitiveness impacts of climate change mitigation policies. The Competitiveness Impacts of Climate Change Mitigation Policies.

Amars L., Fridahl M., Hagemann M., Röser F., Linnér B.O., 2017. The transformational potential of Nationally Appropriate Mitigation Actions in Tanzania: Assessing the concept's cultural legitimacy among stakeholders in the solar energy sector. Local Environment 22(1): 86-105. DOI 10.1080/13549839.2016.1161607.

Amiranashvili A.G., Amiranashvili V.A., Gzirishvili T. G., Kharchilava J.F., TavartkilaZe K. A., 2005. Modern climate change in Georgia. Radiatively active small atmospheric admixtures.

Baba N., 2010. Indonesia: A vulnerable country in the face of climate change. Global Majority E-Journal 1(1): 31-45.

Badan Pusat Statistik., 2019. Statistical Yearbook of Indonesia 2019. Statistik Indonesia 2019 (Indonesian Statistics). Badan Pusat Statistik, Jakarta.

Barichello R.R., Patunru A., 2009. Agriculture in Indonesia: Lagging performance and difficult choices. Choices 24(2): 37-41. Online: http://www.cabdirect.org/abstracts/20113007308.html (accessed May 31, 2021).

Bollen J., Guay B., Jamet S., Corfee-Morlot J., 2009. Co-benefits of climate change mitigation policies: Literature review and new results. OECD 693: 46. DOI $10.1787 / 224388684356$.

Büchs M., Bardsley N., Duwe S., 2011. Who bears the brunt? Distributional effects of climate change mitigation policies. Critical Social Policy 31(2): 285-307. DOI 10.1177/0261018310396036.

Conway D., Schipper E.L., 2011. Adaptation to climate change in Africa: Challenges and opportunities identified from Ethiopia. Global Environmental Change 21(1): 227-237. DOI 10.1016/j.gloenvcha.2010.07.013.

Energy Research Centre of the Netherlands (ECN): Lachlan Cameron, Natalie Harms, X. van T., Gardiner, E. A., Fridahl, C. for C. S. and P. R. (CSPR): M., Center for Clean Air Policy (CCAP): Stacey Davis, H. P. - chapter Financing Nama. and Indc., GIZ: Heiner von Luepke, Lisa Herrmann, I. Z. - chapter Stakeholder engagement, NewClimate Institute: Thomas Day, F. R. - chapter Assessing impacts and benefits, WRI: Kelly Levin - chapter Measurement, R. and V. (MRV), \& Frameworks, U. J. V. - chapter Institutional. (2015). NAMAs and INDCs Interactions and opportunities.

Farooq M.B., 2015. Qualitative telephone interviews: Strategies for success. 18th Annual Waikato Management School Student Research Conference: 1-30.

Friman M., Upadhyaya P., Linnér B.O., 2014. Supporting Nationally Appropriate Mitigation Actions through the Green Climate Fund: Governance capacities and challenges. Internalising Mitigation Activities into the Development Priorities and Approaches of Developing Countries 65.

Gashaw T., Mebrat W., Hagos D., Nigussie A., 2014. Review on climate change adaptation and mitigation mechanisms in Ethiopia. Journal of Biology, Agriculture and Healthcare 4(15): 148-153.

Georgia's Second National Communication to the UNFCCC Tbilisi., 2009.

Georgia's Third National Communication to the UNFCCC., 2015.

Government of Ethiopia., 2015. Second National Communication Report to the UNFCCC.

Hussein Z., Hertel T., Golub A., 2013. Climate change mitigation policies and poverty in developing countries. Environmental Research Letters 8(3): 035009. DOI 10.1088/17489326/8/3/035009.

IRENA., 2014. IRENA Handbook on Renewable Energy Nationally Appropriate Mitigation Actions (NAMAs). 2nd edition (December).

Jung M., Eisbrenner K., HÖHNE N., 2010. How to get Nationally Appropriate Mitigation Actions [NAMAs] to work. ECOFYS Policy Update 11.2010, 11.

Linnér B.O., Pahuja N., 2012. A registry of nationally appropriate mitigation actions: Goals, outcomes, and institutional requisites. AMBIO 41(1): 56-67. DOI 10.1007/ s13280-011-0241-6. 
Lo-lacono V., Symonds P., Brown D.H., 2016. Skype as a tool for qualitative research interviews. Sociological Research Online. Online: 1-25. https://www.socresonline.org. uk/21/2/12.html (accessed May 31, 2021).

MENRPG., 2015. Georgia's Third National Communication to the UNFCCC.

Metz B., 2007. Intergovernmental Panel on Climate Change (IPCC), 2007. Climate change 2007: Mitigation. Contribution of Working Group III to the Fourth Assessment Report of the Intergovernmental Panel on Climate Change. Cambridge Univ. Press, Cambridge and New York.

Metz B., Kok M., 2008. Integrating development and climate policies. Climate Policy 8(2): 99-102. DOI 10.3763/ cpol.2008.0523.

Michaelowa K., Michaelowa A., 2012. Negotiating climate change. Climate Policy 5(12): 527-533.

Permadi D.A., Sofyan A., Oanh N.T., 2017. Assessment of emissions of greenhouse gases and air pollutants in Indonesia and impacts of national policy for elimination of kerosene use in cooking. Atmospheric Environment 154: 82-94. DOI 10.1016/j.atmosenv.2017.01.041.

Peskett L., Brown J., 2011. Climate finance in Indonesia: Lessons for the future of public finance for climate change mitigation. Development 11: 55.

Rizaldi B., Retno Gumilang Dewi M., Ardiansyah Ucok W., Siagian A.F., Roland Barkey I., Wayan Suadnya I.S., Alan Koropitan Perdinan A.B., 2017. Indonesia Third National Comunication.

Robinson S., Strzepek K., Cervigni R., 2013. The cost of adapting to climate change in Ethiopia: Sector-wise and macro-economic estimates. 53: 1-26.

Röser F., van Tilburg X., Davis S., Höhne N., Cameron L., Würtenberger L., Bakker S., Movius D., Houdashelt M., Helme N., 2012. Annual status report on nationally appropriate mitigation actions (NAMAs). Mitigation Momentum, Ecofys and ECN.

Sharma S., Desgain D., 2013. NAMAs Temperature Legal of.
Sundstrom K.H., Sundstrom L.M. (Ed.)., 2010. Global commons, domestic decisions. The comparative politics of climate change. The MIT Press, Cambridge, Massachusetts.

Susandi A., 2004. The impact of international greenhouse gas emissions reduction on Indonesia Armi Susandi Berichte zur Erdsystemforschung.

Swithin L., 2018. Implementation of Nationally Determined Contributions Georgia Country Report.

Thuy P.T., Moeliono M., Locatelli B., Brockhaus M., Gregorio M.D., Mardiah S., 2014. Integration of adaptation and mitigation in climate change and forest policies in Indonesia and Vietnam. Forests 5(8): 2016-2036. DOI 10.3390/ f5082016.

UNFCCC., 2009. Report of the Conference of the Parties on its fifteenth session, held in Copenhagen from 7 to 19 December 2009. Distr. GENERAL FCCC/CP/2009/11/Add.1 30 March 2010.

UNFCCC., 2010. Report of the Conference of the Parties on its sixteenth session, held in Cancun from 29 November to $10 \mathrm{De}$ cember 2010./ CP/2010/7.

UNFCCC., 2013. First annual report to the Conference of the Parties on the operation of the registry of nationally appropriate mitigation actions./CP/2013/I.

United Nations., 2019. World population prospects 2019. In Department of Economic and Social Affairs. World Population Prospects 2019. (Issue 141).

Upadhyaya P., Linnér B.O., 2012. Financing Nationally Appropriate Mitigation Actions: A phased approach. Linköping University Electronic Press.

USAID., 2016. Greenhouse gas emissions in Georgia.

World Resources Institute., 2017. How can Indonesia achieve its climate change mitigation goal? An analysis of potential emissions reductions from energy and land-use policies.

Zerga B., Gebeyehu G., 2016. Climate change in Ethiopia variability, impact, mitigation, and adaptation. Journal of Social Science and Humanities Research 2(4): 66-84. 